\title{
Mesmo longe estamos perto de nossos alunos: Avaliação do encontro presencial do curso de Especialização em Negociação Coletiva modalidade EaD - UFRGS/MPOG
}

\author{
Elaine Di Diego Antunes, EA/UFRGS, eddantunes@ea.ufrgs.br \\ Diogo Joel Demarco, EA/UFRGS, djdemarco@ea.ufrgs.br \\ Rosária Lanziotti Moraes, PEAD/UFRGS, rlmoraes@ea.ufrgs.br \\ Nádia Brunetta, EA/UFRGS, nabrunetta@yahoo.com.br
}

\begin{abstract}
Resumo
O presente trabalho tem como objetivo analisar as atividades realizadas durante o encontro presencial de formação dos Servidores Públicos Federais do Poder Executivo, matriculados no Curso de Especialização em Negociação Coletiva ${ }^{1}$ - modalidade à distância. As atividades realizadas neste encontro foram elaboradas com o propósito de possibilitar momentos de integração e interação entre seus participantes, bem como proporcionar uma revisão (coletiva) das matérias estudadas no curso e se constituir, em si, elemento de avaliação. Com a finalidade de identificar se o encontro atingiu os objetivos propostos, realizou-se um estudo de caso de natureza exploratória-descritiva, através da coleta de depoimentos de dezoito tutores que mediaram às dinâmicas ${ }^{2}$ especialmente preparadas para esta avaliação presencial acerca do trabalho coletivo realizado em cada Pólo, além de uma avaliação online realizada com o os alunos, através da Plataforma Interativa de Aprendizagem (NAVi). De acordo com os resultados obtidos, através da técnica de análise de conteúdo, a experiência foi muito gratificante, pela afetividade, envolvimento e empenho demonstrados pelos alunos durante a realização das atividades propostas. Estes dados permitem concluir que mesmo que o curso seja na modalidade à distância, há muita proximidade e interação entre e com os alunos e tutores no processo de formação de servidores.
\end{abstract}

Palavras-chave: Interação; Teoria; Prática; Formação

\section{Even away we are close to our students: Evaluation from the presence meeting of Specialization Course in Collective Bargaining on virtual learning - UFRGS / MPOG}

\begin{abstract}
This paper aims to analyze the activities developed during the meeting for training/preparation of Federal Public Servers from the Brazilian Executive Power registered on Specialization Course in Collective Bargaining through online learning.

\footnotetext{
${ }^{1}$ Empreendimento conjunto entre o Ministério do Planejamento, Orçamento e Gestão e o Programa de Pós-Graduação em Administração da Universidade Federal do Rio Grande do Sul.

${ }^{2}$ Caso Eleuthera, Caso Latínia e Mapas Conceituais.
} 
The activities were elaborated in order to provide moments of integration and interaction between the participants as well to provide a review (collective) about the subjects taught during the course and to constitute itself an element of evaluation. Intending to identify whether the meeting had achieved its objectives, we conducted an exploratory case study. Data were collected based on testimonies of eighteen tutors who brokered the dynamics, which was specially prepared for this meeting assessment about the collective job done in each city. It was employed too an assessment conducted online with students through the Interactive Learning Platform. According to the results, the experience was very rewarding, by affection, involvement and commitment shown by students during the performance of the proposed activities. The meeting face to suggest that even if the course is ministered on distance, there is much closeness and interaction with and between students and tutors in the server`s formation process.

Keywords: Interaction; Theory; Practice; Formation.

\section{Introdução}

A questão das relações de trabalho no setor público tem sofrido transformações profundas nos últimos anos, principalmente, em decorrência da política de governo, que estabeleceu processo sistemático de democratização das relações de trabalho na administração pública federal, através da instituição de mesas de negociação com o conjunto dos representantes das entidades sindicais dos servidores públicos. Esta nova dinâmica apontou a necessidade de estabelecimento jurídico-formal com a definição do marco regulatório adequado à institucionalização da negociação na administração pública federal.

Neste contexto, fica evidente a necessidade de capacitação dos servidores públicos e, assim, destaca-se como objetivo do curso de especialização proposto a contribuição no processo de institucionalização da negociação coletiva na Administração Pública Brasileira, fomentando uma mudança de cultura no âmbito das relações de trabalho nas organizações públicas brasileiras, criando uma massa crítica de servidores públicos federais - da administração direta, autárquica e fundacional capazes de atuar nos processos de negociação coletiva no setor público. O Curso de Especialização em Negociação Coletiva, empreendimento conjunto entre o Ministério do Planejamento, Orçamento e Gestão e o Programa de Pós-Graduação em Administração da Universidade Federal do Rio Grande do Sul, foi organizado com a intenção de promover momentos de interação entre seus participantes e promover a aplicabilidade dos conteúdos teóricos desenvolvidos nas disciplinas, no contexto profissional dos servidores públicos.

Para atender os objetivos de mediação do conhecimento e interação, o acompanhamento tutorial torna-se elemento fundamental e assegura o desenvolvimento e o aproveitamento dos eventos realizados no curso a distância. Assim, o sistema de tutoria, muito mais que um aspecto estrutural e de apoio ao estudante, é visto como o atendimento à educação individualizada e colaborativa, isto é, como uma estratégia de abordagem pedagógica centrada no ato de aprender que põe à disposição do estudante todos os recursos que irão permitir a consecução dos objetivos previstos no curso, desenvolvendo nos alunos uma maior autonomia em seu percurso de aprendizagem. Nesta perspectiva, a função dos professores e tutores é de promover a aprendizagem, através de um processo de diálogo onde o conhecimento é produzido a partir deste movimento, entre tutores, professores, alunos, avaliação e conteúdos (Nevado, 2005). 
Em situações de educação a distância ${ }^{3}$, esta interação entre professores-alunos, tutores e alunos e alunos-alunos é um fator extremamente importante e eficaz no processo de ensino-aprendizagem. Belloni (2003, p. 48) usa o termo "conversação didática orientada" para ressaltar a importância deste mediador, seja ele tutor ou professor, estar em constante diálogo com seus alunos, com o objetivo de estimulá-los durante todo o processo e principalmente mostrar que não estão sozinhos, contribuindo para que não desistam do processo de formação.

O curso de especialização em Negociação Coletiva é desenvolvido na Plataforma NAVi, um ambiente virtual no qual ocorrem as interações entre os alunos (as), professores (as) e tutores(as), através da utilização de diferentes recursos e funcionalidades que facilitam o aprendizado. Além das disciplinas cursadas a distância foi promovido um encontro presencial, com o propósito de possibilitar a interação dos alunos que até então só tinham contato através do ambiente e constituir etapa de avaliação dos conhecimentos obtidos pelos alunos.

Este encontro teve como propósito complementar o processo de ensinoaprendizagem à distância iniciado em junho de 2009, com 574 discentes (todos servidores públicos federais) matriculados, em sete pólos do país: Belém (PA); Belo Horizonte (MG); Brasília (DF); Porto Alegre (RS); Recife (PE); Rio de Janeiro (RJ) e São Paulo (SP). Tendo em vista a realização deste evento, a questão norteadora desta pesquisa é: Como os tutores e alunos avaliam sua participação no encontro presencial do curso de Negociação Coletiva frente às atividades propostas? Esta reflexão permite uma avaliação das dinâmicas aplicadas no encontro presencial, bem como do curso de qualificação realizado com os tutores. Tal movimento de ação-reflexão-ação em relação a nossa prática torna-se fundamental para compreender este processo de construção da nossa ação. Assim é possível contemplarmos na prática o que defendemos na teoria.

\section{O processo de ensino-aprendizagem mediado por tecnologias}

Na educação mediada por tecnologias, se quisermos desenvolver uma prática colaborativa e cooperativa precisamos ter a sensibilidade de ouvir e respeitar o outro. Neste processo é possível perceber que "quem ensina aprende ao ensinar e quem aprende ensina ao aprender" (Freire, 2000, p. 23). Nesse sentido, Silva (2006) reconhece a interatividade como "o espírito de um novo tempo, uma revolução na comunicação”. Aproxima-se, assim, tanto interação quanto interatividade do universo da comunicação, muito mais que da informática (Litto, 2009). Abordando o ensino a distância como palco do ensino e da interatividade, lembremos que sua maior contribuição está na possibilidade de separação física entre professor e aluno, sem que, com isso, se perca o caráter de interação - síncrona ou assíncrona - do processo, mantendo-se a relação tríadica característica do processo de ensino. A EaD utiliza-se de meios técnicos para garantir essa interação, flexibilizando o aprendizado em termos temporais e locais. Inegável, no entanto, as relações interativas (Litto, 2009) que se estabelecem nessa opção de ensino entre:

- Aluno/professor: há autores que defendem que este processo de interação ocorre efetivamente quando o circuito de mensagens flui entre os personagens. Assim, a interação somente aconteceria se o professor, ao responder um questionamento do

\footnotetext{
${ }^{3}$ Conforme Belloni (2003) educação a distância é uma relação de diálogo, estrutura e autonomia que requer meios técnicos para mediatizar esta comunicação. É baseada em procedimentos que permitem o estabelecimento de processos de ensino-aprendizagem mesmo onde não existe contato face a face entre professores e alunos.
} 
aluno, recebesse seu feedback e fizesse um novo comentário, como num debate em que houvesse a "réplica" e a "tréplica”, por exemplo.

- Aluno/conteúdo: os alunos podem interagir com diferentes conteúdos e objetos de aprendizagem, tais como: som, texto, imagens, vídeos, etc., através da navegação, exploração, seleção e controle.

- Aluno/aluno: pode ocorrer síncrona e assincronamente, caracterizando o que se denomina aprendizado colaborativo e cooperativo. Essa interação desenvolve o senso crítico e a capacidade de trabalhar em equipe, podendo criar a sensação de pertencer a uma comunidade.

A importância destes momentos de interação entre os participantes do curso é descrita por Maçada e Tijiboy (1998. p.3) como:

(...) a interação ("inter-ação") é o elemento básico e inicial de todo o processo, pois é ela que abre o canal de comunicação. Mas ela também está e deve estar presente ao longo de todo o trabalho em grupo possibilitando uma negociação constante entre os sujeitos envolvidos. Viabilizando o aprendizado através das relações inter-pessoais.

Outros tipos de interação possíveis são mencionados por diversos autores (Nevado, 2005; Belloni, 2003; Almeida, 2003), alguns propõem classificação em função dos agentes envolvidos, outros observam a influência mútua entre o aluno e seu entorno e há ainda os que defendem uma interatividade social, que incluiria aspectos da comunicação como linguagem corporal, troca de informações pessoais e motivação do aluno, num contexto que iria para além da sala de aula. Independente do tipo é importante considerar que o grau das interações varia em função das mídias utilizadas e a combinação planejada dessas diferentes formas de interação é um dos desafios da EaD.

\section{Metodologia}

A presente pesquisa é um estudo de caso, por estudar um fenômeno contemporâneo num determinado contexto (Yin, 2001). O estudo adota uma perspectiva exploratória por tratar de algo pouco estudado, ou seja, o objeto analisado refere-se ao encontro presencial num curso de educação à distância no campo da administração pública federal. A pesquisa foi elaborada com base em dados primários extraídos de informações coletadas junto aos dezoito tutores que moderaram as dinâmicas aplicadas no encontro presencial de alunos que nunca haviam se encontrado anteriormente, apesar de estarem convivendo à distância à quase um ano através de chats, fóruns e outras atividades.

Os tutores selecionados para participarem do encontro presencial foram escolhidos por já haverem participado da tutoria no decorrer do curso, obtendo avaliações bastante satisfatórias por parte dos alunos. Além disto, alguns destes foram tutores facilitadores, ou seja, atuaram como mediadores entre a coordenação do curso, os professores da disciplina e seus colegas. Os participantes deste estudo elaboraram um relatório descritivo, no qual avaliaram as atividades desenvolvidas com sua turma no encontro presencial. Em seus comentários foram apresentadas percepções acerca da turma, destacando, por exemplo, o desempenho do grupo, nível de interesse individual e de satisfação dos alunos, a avaliação da infra-estrutura de cada Pólo, e, sobretudo, a avaliação das dinâmicas aplicadas com fins didático-pedagógicos específicos, como mostramos mais adiante. 
Além dos relatórios enviados pelos tutores, duzentos e nove alunos responderam a avaliação do encontro pela Plataforma NAVi. Este instrumento segue o modelo de avaliação realizado ao final das disciplinas do curso. Em cada item há uma escala com seis possibilidades de resposta: Discordo plenamente; Discordo; Não concordo, nem discordo; Concordo; Concordo Plenamente; Não se aplica. A opção 'Não se aplica' deve ser assinalada nos casos em que não for possível ao aluno, por qualquer motivo, avaliar quaisquer dos itens do Instrumento de Avaliação. No final da avaliação, há um espaço aberto para críticas, sugestões, elogios, enfim, para as considerações do aluno em relação ao Encontro Presencial. Os resultados foram mensurados através de gráficos da Plataforma Navi:

"Utilizou-se a técnica de análise de conteúdo para interpretar os relatos dos tutores e alunos. A análise de conteúdo é considerada uma técnica para o tratamento de dados que visa identificar o que está sendo dito a respeito de determinado tema" (Vergara, 2005, p. 15). “A finalidade da análise de conteúdo é produzir inferência, trabalhando com vestígios e índices postos em evidência por procedimentos mais ou menos complexos” (Puglisi; Franco, 2005, p. 25).

\section{Resultados e Discussão}

Nos dias 15 e 16 de abril de 2010 foram realizados os encontros presenciais previstos, nos Pólos de Belém (PA); Belo Horizonte (MG); Brasília (DF); Porto Alegre (RS); Recife (PE); Rio de Janeiro (RJ) e São Paulo (SP), correspondentes às cidades em que os alunos se inscreveram para realização do curso na modalidade a distância. A tabela abaixo mostra o número de alunos matriculados no curso, indicando o número de presentes e de faltantes no encontro presencial:

Tabela 1: Distribuição e participação dos alunos conforme os pólos

\begin{tabular}{|l|l|c|c|c|}
\hline & PÓLO & ALUNOS MATRICULADOS & PRESENTES & FALTANTES \\
\hline 1 & Belém & 65 & 45 & 20 \\
\hline 2 & Belo Horizonte & 33 & 21 & 12 \\
\hline 3 & Brasília & 151 & 106 & 45 \\
\hline 4 & Porto Alegre & 86 & 66 & 20 \\
\hline 5 & Recife & 98 & 65 & 33 \\
\hline 6 & Rio de Janeiro & 56 & 42 & 14 \\
\hline 7 & São Paulo & 84 & 69 & 15 \\
\hline
\end{tabular}

A abertura dos trabalhos foi realizada na manhã do dia 15 de abril, pela da Secretaria de Recursos Humanos do Ministério do Planejamento e Orçamento (MPOG), através de vídeo-conferência com a presença do Secretário da SRH-MPOG, da diretora da ENAP e da diretora do MPOG e do reitor da UFRGS. De acordo com os relatos, a fala dos representantes do MPOG presentes nos encontros, foi motivadora e esclarecedora, trazendo inclusive uma "revisão" de conteúdos sobre o histórico da Negociação Coletiva no país e o cenário atual. Em seguida, foi aberto um espaço para questionamentos, com bastante participação dos alunos presentes. Em alguns locais como Belém, Rio de Janeiro e São Paulo algumas adequações foram necessárias em virtude de contratempos locais que inviabilizaram este primeiro momento.

A criatividade e autonomia dos tutores e professores de cada Pólo permitiram que as atividades programadas fossem realizadas mesmo com algumas adaptações de metodologia e horários. Estas atividades foram elaboradas especialmente para atender 
aos seguintes objetivos: integrar os participantes; proporcionar uma revisão (coletiva) das matérias estudadas no curso e, se constituir, em si, em elemento de avaliação.

Inicialmente, foi aplicada uma dinâmica de integração que teve duplo objetivo: promover a integração de todos os presentes e resgatar os princípios e o dilema entre a cooperação e a competição através da Teoria dos Jogos, abordando um tema já tratado na disciplina Estado, Governo e Sociedade. Esse teve a sua aplicabilidade colocada em prática através do jogo conhecido como o Dilema do Voluntário; na seqüência, embora simulada, foi realizada uma dinâmica de Negociação que possibilitou vivenciar um efetivo embate entre os vários atores e os conflitos que os situam nos lados opostos de uma Mesa de Negociação Coletiva Estatal, quando então os participantes puderam colocar em prática as estratégias e os estilos estudados nas disciplinas de Negociação I, II e III; no período vespertino, os alunos organizados em grupos e com o apoio do software CMap Tool elaboraram os Mapas Conceituais das seis disciplinas estudadas: Estado, Governo \& Sociedade; Ética, Cultura \& Valores; Relações e Organização do Trabalho, Negociação I, II e III. A proposta da elaboração dos mapas conceituais tinha como objetivo possibilitar a visualização da integração dos conteúdos das diferentes disciplinas. Na dinâmica de integração os alunos foram divididos em duplas e foram orientados a apresentarem o colega. Sobre esta dinâmica, o Tutor de Recife (GRUPO A) relatou:

A dinâmica foi bem divertida e os alunos mostram-se acolhedores. No final da atividade um aluno pediu a palavra para debater com os colegas sobre a motivação em trabalhar no serviço público. Fato que gerou um breve debate. Percebi, neste momento, que os alunos gostariam de um tempo maior durante o Encontro Presencial para debater sobre suas condições de trabalho. Uma sugestão para próximos cursos.

Conforme o relatório da tutora do Pólo de Porto Alegre, a dinâmica sobre o caso Eleuthera foi muito interessante, os alunos se envolveram bastante e perceberam que para realizar esta atividade era importante cooperar ao invés de pensar em benefício próprio:

Foi salientado ao final da dinâmica, que mesmo com a intenção de beneficiar a todos, não era uma boa estratégia agir sozinho, mas tentar procurar uma solução conjunta, onde todos pudessem opinar. O índice de cooperação foi de $70 \%$, índice bastante alto em comparação com as outras turmas. Não foi possível desenvolver a atividade no tempo previsto de 30 minutos.

A maioria dos tutores relatou que a primeira dinâmica ultrapassou o tempo previsto, portanto algumas alterações foram providenciadas nos Pólos. Assim sobre o desenvolvimento do Caso Latínia em Recife (GRUPO A) temos o seguinte relato:

Os alunos incorporaram bem o espírito da dinâmica, assumindo os papéis que estavam representando. Fiz cinco rodadas de perguntas e solicitei que cada grupo apresentasse seus objetivos. Neste momento, os alunos assumiram a postura de negociadores e começaram a "vender" suas idéias para atingir seus objetivos. Os representantes dos ministérios solicitaram o formulário para a elaboração de um projeto de lei. Os representantes do Ministério do Planejamento criaram um projeto para a implementação de um sistema de transporte Compartilhado S.A (...) A mesa de negociação foi formada enquanto o parlamento votava os projetos de lei propostos pelos ministérios. Apenas o Ministério do Bem Estar Social teve seu projeto aprovado. Realizamos, por fim, a eleição dos partidos. 
Muitos tutores relataram que não houve tempo suficiente para construção dos Mapas Conceituais e adotaram a estratégia de distribuir os mapas, que haviam sido elaborados previamente pelos professores responsáveis pelas disciplinas, para os alunos analisarem e apresentarem posteriormente para a turma. Cabe destacar alguns dos depoimentos desta etapa. A Tutora do Pólo de Belém afirmou em seu relatório que:

Os alunos gostaram bastante da atividade. Os mais interessados e empolgados ficaram lá até 30 minutos depois, debatendo sobre como o espírito de colaboração é importante na negociação.

Tutora do Pólo de Belo Horizonte:

Posso dizer que, apesar dos atrasos, em não conseguir fechar as atividades no tempo pré-estabelecido, os alunos adoraram as dinâmicas, elogiaram e conseguiram captar as mensagens que planejamos e principalmente, compreender a teoria e adaptá-la na prática proposta.

Da mesma forma que a avaliação realizada junto aos tutores demonstrou um resultado bastante satisfatório, a avaliação efetuada com os alunos evidenciou concordância de opiniões entre estes atores. A tabela abaixo permite constatar que a maioria dos alunos respondentes avaliou positivamente os principais critérios planejados para o encontro presencial, especialmente no que tange à forma de avaliação (individual e grupal), a qualidade das dinâmicas, a pertinência de seus conteúdos, bem como a condução e orientação participativa dos tutores. A avaliação favorável destas variáveis é corroborada pelo índice observado no item que verifica o atingimento das expectativas dos alunos.

Tabela 2: Síntese da Avaliação dos Alunos

\begin{tabular}{|l|c|}
\hline \multicolumn{1}{|c|}{ Variável de avaliação } & $\begin{array}{c}\text { Grau de } \\
\text { concordância } \\
\text { (concordo/concordo } \\
\text { plenamente) }\end{array}$ \\
\hline Os critérios e tipos de avaliação presencial foram apropriados. & 79,43 \\
\hline A qualidade das atividades em grupo foi satisfatória. & 79,43 \\
\hline $\begin{array}{l}\text { Os conteúdos das dinâmicas foram condizentes com o que foi } \\
\text { estudado no curso. }\end{array}$ & 86,60 \\
\hline $\begin{array}{l}\text { O tutor incentivou a participação dos alunos nas atividades, } \\
\text { promovendo o debate e valorizando as contribuições de todos. }\end{array}$ & 94,66 \\
\hline $\begin{array}{l}\text { Minhas expectativas em relação ao Encontro Presencial foram } \\
\text { atendidas. }\end{array}$ & 81,82 \\
\hline
\end{tabular}

Ademais, os alunos destacaram em seus depoimentos a importância de conhecer e conversar pessoalmente com os colegas e tutores da turma; a satisfação com a qualidade e eficácia do material didático e com as dinâmicas aplicadas no encontro; a qualidade da palestra realizada em cada Pólo por um representante do Ministério do Planejamento, Orçamento e Gestão, realizada na abertura do encontro e a elaboração dos Mapas Conceituais - que permitiram a percepção da integração dos conteúdos ministrados nas disciplinas do curso. O depoimento abaixo ilustra a resposta de vários alunos. 
como a participação da tutora foram excelentes. No entanto, em Recife tivemos um pouco de contratempo, pois faltou energia bem na hora da apresentação do ministro. No mais foi muito gratificante poder conhecer os colegas e alguns tutores. Parabéns a todos que fazem esse curso acontecer! (Depoimento de Aluno)

Para condução das atividades nos Pólos, os tutores demonstraram autonomia e criatividade. Estas habilidades possibilitaram que as atividades programadas fossem realizadas a contento, mesmo com algumas adaptações de metodologia e flexibilização de horários, necessários para atendimento de percalços e imprevistos que aconteceram de maneira pontual (como a queda de energia ou falha na conexão de internet, ocorrida em alguns Pólos). Para finalizar, fica assim evidente que a atuação do tutor foi fundamental para a condução dos trabalhos no encontro presencial, como demonstra o relato a seguir:

Realmente o encontro foi um grande acontecimento para nós enquanto alunos e acredito que para os tutores, professores e coordenadores também. Mas realmente o tempo foi curto, parcimônia total, pois a curiosidade era muita e nos detemos tanto em nos comunicar com os atores deste curso que as atividades eram dadas e nós já nos dispersávamos e demorávamos a retomada das atividades, os tutores se desdobravam para vencer o tempo estipulado. Tínhamos muita matéria acumulada para este encontro e eu realmente me perdi na organização da minha agenda e não estudei o suficiente. $\mathrm{Na}$ real, o nosso compromisso com nossas atividades profissionais nos detêm ocupados por longo período o que resulta em pouco tempo para estudos (Depoimento de Aluno).

\section{Conclusões}

De maneira geral os alunos gostaram de conhecer presencialmente os colegas, elogiaram as atividades desenvolvidas e, apesar do curto espaço de tempo, parabenizaram a condução dos tutores, saindo satisfeitos do encontro presencial. De acordo com os resultados obtidos, a experiência foi gratificante pela afetividade, envolvimento e empenho demonstrados pelos alunos durante a realização das atividades propostas. Entende-se que no curso mesmo sendo na modalidade à distância, há muita proximidade e interação entre e com os alunos e tutores no processo de formação de servidores. Ademais, o Encontro permitiu que fosse experimentada na prática a teoria estudada a partir de uma postura ativa dos participantes.

Na opinião dos tutores, os alunos de todos os Pólos demonstraram bastante envolvimento e consideraram as dinâmicas aplicadas interessantes, porém destacaram que se tivessem mais tempo poderiam ter alcançado melhores resultados. Certamente as sugestões, críticas e elogios expressados pelos discentes servirão para reestruturação dos encontros presenciais em novas ofertas de cursos e possibilitarão um estreitamento das relações entre os alunos, tutores e professores. Trata-se da evolução do sistema tradicional de aulas em benefício de um método de ensino onde o professor e o tutor são os mediadores enquanto o aluno é um sujeito ativo no processo de ensino-aprendizagem construindo seu conhecimento através de articulações pedagógicas que envolvem atividades presenciais e de autoestudo, individuais e em grupos.

Assim, o Curso de Especialização em Negociação Coletiva, empreendimento conjunto entre o Ministério do Planejamento, Orçamento e Gestão e o Programa de PósGraduação em Administração da Universidade Federal do Rio Grande do Sul, busca por meio da proposição de uma articulação pedagógica dos conteúdos, possibilitar ao aluno uma visão ampla do processo e da construção do aprendizado de forma gradativa e 
integrada, com o objetivo de desenvolvimento de competências, apoiando-se em tecnologias de ensino e aprendizagem. Essa perspectiva centra-se na construção de competências e habilidades voltadas a uma ação teórico-prática, adotada no curso, preparando o servidor público, estimulando o domínio das competências necessárias para o desempenho das atividades desenvolvidas nas diversas situações de seu trabalho.

\section{Referências Bibliográficas}

ALMEIDA, Maria Elizabeth Biancocini. Tecnologia e Educação a Distância: Abordagens e Contribuições dos Ambientes Digitais e Interativos de Aprendizagem. ANPEd, 2003.

BELLONI, Maria Luiza. Educação à distância. 3. ed. Campinas: Autores Associados, 2003.

FREIRE, Paulo. Pedagogia da autonomia: saberes necessários à prática educativa. 16.ed. Rio de Janeiro: Paz e Terra, 2000.

LITTO, Fredic Michael; FORMIGA, Manuel Marcos Maciel (Orgs). Educação a distância: o estado da arte. São Paulo: Pearson Education do Brasil, 2009.

MAÇADA, L.Débora; TIJIBOY, Ana Vilma. Aprendizagem Cooperativa em Ambientes Telemáticos. IV Congresso RIBIE, Brasília 1998. Disponível em http://lsm.dei.uc.pt/ribie/docfiles/txt200342414721274.PDF Acesso em: 8 maio.2010.

NEVADO, Rosane Aragon de. Ambientes virtuais de aprendizagem: do "ensino na rede" à "aprendizagem em rede". Disponível em <http://www.tvebrasil.com.br/salto/boletins2005/nfa/tetxt2.htm> Acesso em: 8 maio.2010.

SILVA, Marcos. Sala de Aula Interativa, 4. Ed. Rio de Janeiro: Quartet, 2006.

PUGLISI, M.L.; FRANCO, B. Análise de conteúdo. 2. ed. Brasília: Líber Livro, 2005.

VERGARA, S.C. Projetos e relatórios de pesquisa em Administração. 4. ed. São Paulo: Atlas, 2005. 